\title{
Change for success
}

\section{Substantial reform of science administration in India is needed for the country to increase its global scientific impact.}

The Indian general elections, which concluded in May of this year, were a historic event for the country. With over 800 million registered voters, it was the largest electoral event in the world. After being in opposition for over a decade, the Bharitiya Janata Party obtained over $30 \%$ of the vote and over $50 \%$ of the seats, which guarantees that they can govern without needing to form a coalition with other parties.

The new Prime Minister Narendra Modi and his cabinet have a demanding task ahead of them. They need to reinvigorate economic growth, which has slowed down in recent years, improve infrastructure in the country, and combat corruption and crime. Within the scientific community, there are therefore concerns that research will not be considered a priority. These concerns have been solidified by the fact that the new minister for science, Jitendra Singh, was not given cabinet rank and was instead inducted as a junior minister.

India has a tradition in science that goes back centuries, and includes a number of notable early mathematicians. More recently, and in the first half of the twentieth century in particular, it includes C. V. Raman, who developed the type of spectroscopy that carries his name and earned him the Nobel Prize in Physics, and S. N. Bose, whose work became the foundation of what is now known as Bose-Einstein statistics. From the second half of the twentieth century, however, the country has struggled to keep pace with scientific advances elsewhere in the world.

In the past few years, things have improved, especially with the creation of a number of specialized research centres. Institutes such as the Indian Institute of Science, the Indian Institutes of Technology, the Tata Institute for Fundamental Research, and the Jawaharlal Nehru Centre for Advanced Scientific Research are producing high-quality science on a regular basis. Nevertheless, the global scientific impact of the country must grow.

In a Commentary in this issue Arindam Ghosh and Yamuna Krishnan take nanotechnology as an example to explore recent positive signs for science in the country, and highlight various aspects that still need to improve ${ }^{1}$. Past governments have supported nanotechnology with specific programmes such as the Nano Science and Technology Initiative, and with the Nano Mission. Hundreds of individual projects were funded, and numerous nanoscience and nanotechnology institutes created. As a result, the number of papers and patents increased, as did the number of graduate students working in the field.

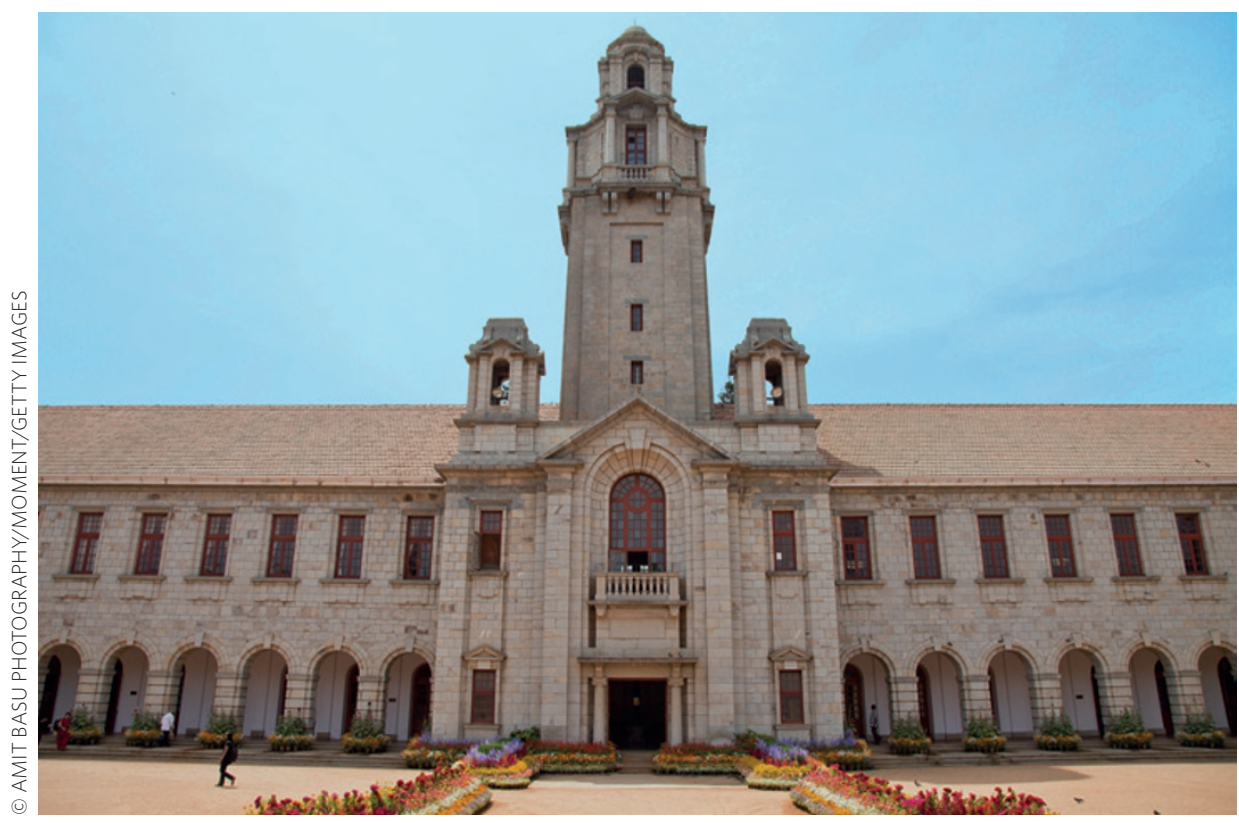

The Indian Institute of Science in Bangalore.

A lot more still needs to be done though. The increase in number of publications has not been matched by a rise in scientific impact, as measured by the number of citations. And although this dedicated funding is important, it is still small compared with other countries. In the past twenty years, science investment has been constantly below $1 \%$ of the gross domestic product, unlike other emerging economies such as China, South Korea and Brazil ${ }^{2}$.

Funding must rise, but it is not the only problem. As Ghosh and Krishnan argue, changes are needed in the way science is administered. More emphasis should be placed on creating national consortia and international collaborations. The bureaucracy of science should be simplified to speed up the time it takes to allocate funding and ensure that Indian scientists can keep up with competitors elsewhere.

A more fundamental issue in the country is the way in which science is perceived by society, and this situation will only improve through changing the way science and technology is taught in schools. Writing in our regular education page, In the Classroom ${ }^{3}$, C. N. R. Rao explains that the quality of education in schools and higher-education institutions across India is very inhomogeneous, and mostly inadequate to instil the necessary attitude about science and technology in young people. Here too, more than just investment is required - a substantial reform of the education system will be needed to improve the situation significantly.

Although scientists have concerns about the new government, the election manifesto of the Bharitiya Janata Party does at least recognize the importance of science and technology and mentions several issues that the party would address ${ }^{4}$. These include the need to encourage international collaborations, the need to intensify the links between academia and industry, and the need to focus on education. It is unclear yet how the government will proceed, but for science in India to thrive on the international stage, both investment and reform will be required.

\section{References}

1. Ghosh, A. \& Krishnan, Y. Nature Nanotech. 9, 491-494 (2014)

2. Joseph, M. \& Robinson, A. Nature 508, 36-38 (2014).

3. Rao, C. N. R. Nature Nanotech. 9, 564 (2014)

4. http://bjpelectionmanifesto.com/pdf/manifesto2014.pdf 